\title{
RISK OF REFRACTURE AFTER REMOVING HIP FIXATION
}

\author{
JONATHAN S. WAND
}

Stewart (1955) demonstrated that the risk of a second hip fracture was up to 20 times greater than that expected for the sex and age of the patient, and that the younger the patient, the greater was the relative risk. Melton et al (1982) confirmed the increased risk of fracture of the contralateral hip but noted that the ipsilateral hip was relatively protected against fracture for the first three years after the initial injury. It has been suggested that this protection might be due to the presence of the fixation device rather than to the strengthening effect of the consolidation of callus. The present study was designed to test this hypothesis by observing which side sustained the second hip fracture following removal of the fixation device.

Materials and methods. Fifty-four patients (nine men and 45 women) who, between 1980 and 1986, had internal fixation devices removed after radiological union of a femoral neck fracture were reviewed. In 30 patients the fracture was subcapital (Garden grade 1 or 2) and in 24 intertrochanteric. Their average age when the implants were removed was 71.9 years (range 54 to 82). Thirty-one patients had been treated with a Richards screw, 23 with AO screws and three with other fixation devices. The indication for removal had been pain over the hip and greater trochanter in 44 cases and deep sepsis in 10. Sixteen of the patients (53\%) who had had a subcapital fracture had radiological evidence of early avascular necrosis, though hip replacement was not clinically indicated. Those patients whose hips had been replaced were excluded from the study. Osteoarthritis was present only in patients with avascular necrosis. The interval between fixation of the fracture and removal of the device was 3.7 years (range 0.8 to 5.3). Most of the patients were permitted only protected weight-bearing for six weeks after the device was removed.

The period of observation for further hip fractures was defined as the interval between removal of the implant and review, death, moving to a new area, or the second hip fracture. The total duration of follow-up was 272 patient-years, with a mean of five years per patient.

J. S. Wand, BSc, FRCS, Senior Orthopaedic Registrar, Medical Research Council Training Fellow

Whittington Hospital, Highgate Hill, London N19, England.

(C) 1990 British Editorial Society of Bone and Joint Surgery

0301-620X/90/1 R54 \$2.00

J Bone Joint Surg [Br] 1990; 72-B: 148-9.
Results. There were 11 second hip fractures, all of which occurred on the contralateral side (Table I). The probability that this could have occurred randomly is 1 in $2^{11}(p=0.0005)$. The second fracture rate was 40.3 fractures per 1000 people per year. The mean age of the patients at the time of the second fracture was 77.4 (range 68 to 86 years) and these fractures occurred a mean of 3.4 years (range 0.7 to 5.2) after removal of the implant. In $73 \%$ of cases the second fracture was the same type as the first. No patient sustained a third hip fracture. None of the patients with second hip fractures were found to have a metabolic bone disease other than osteoporosis.

Table I. Clinical data of patients sustaining a second hip fracture

\begin{tabular}{lll}
\hline & $\begin{array}{l}\text { Intertrochanteric } \\
\text { fracture (ITF) }\end{array}$ & $\begin{array}{l}\text { Cervical } \\
\text { fracture (CF) }\end{array}$ \\
\hline Number of patients & 5 & 6 \\
Sex & $\begin{array}{l}4 \text { female } \\
1 \text { male }\end{array}$ & 6 female \\
Mean age at second fracture (years) & $80.7(76$ to 86$)$ & $74.6(68$ to 79$)$ \\
Type of initial fracture & $3 \mathrm{ITF}$ & $6 \mathrm{CF}$ \\
& $2 \mathrm{CF}$ & \\
Interval between fractures (years) & $3.0(1.0$ to 4.7$)$ & $3.9(0.7$ to 5.2$)$ \\
\hline
\end{tabular}

Discussion. Our findings are in general agreement with those of Finsen and Benum (1986), who reported that refracture of the same hip occurred in only two patients who had had their fixation device removed, while 15 second fractures occurred in the opposite hip over a period of observation of 630 patient-years. Their overall second fracture rate (for both sides) was 26.9 fractures per 1000 patients per year, which was somewhat lower than that in the present study. Boyce and Vessey (1985) reported that the incidence of first hip fractures for both sexes in Oxford in 1983 was 6.24 fractures per 1000 per year for all patients over the age of 65 . Since the present study reveals a fracture rate of 41.5 fractures per 1000 patients per year, there is a relative risk of a second hip fracture of 6.6, a figure rather higher than that reported by Melton et al (1982).

The low incidence of ipsilateral hip fracture following implant removal disproves the hypothesis that it is the implant itself that protects the hip from a second fracture. This protection might be due to reinforcement 
of the femoral neck by consolidated callus, or perhaps to a tendency for the patient to fall away from the side of the previous injury.

Conclusion. If a patient's symptoms warrant removal of the implant used to fix a hip fracture, this can be done without an increased risk of refracture of that hip, provided there is radiological evidence of union of the fracture.

I would like to thank the consultant orthopaedic surgeons at Northwick Park Hospital for permission to report their patients; to Dr Jonathan Reeve of the Bone Disease Research Group for helping with the preparation of this manuscript and the Medical Research Council for their financial support.
No benefits in any form have been received or will be received from a commercial party related directly or indirectly to the subject of this article.

\section{REFERENCES}

Boyce WJ, Vessey MP. Rising incidence of fracture of the proximal femur. Lancet 1985; i:150-1.

Finsen V, Benum P. Refracture of the hip rare after removal of fixation device. Acta Orthop Scand 1986; 57:434-5.

Melton LJ III, Ilstrup DM, Beckenbaugh RD, Riggs BL. Hip fracture recurrence: a population-based study. Clin Orthop 1982; 167:1318

Stewart IM. Fractures of neck of femur: incidence and implications. Br Med J 1955; i :698-701.

\title{
SOURCE OF THE CEMENT WITHIN THE CHARNLEY HIP
}

\author{
G. H. ISAAC, B. M. WROBLEWSKI, J. R. ATKINSON， D. DOWSON
}

We have already reported the damaging effects of intraarticular acrylic cement on both the femoral head and the acetabular cup (Isaac et al 1986). In that series of 59 sockets $51(86 \%)$ showed damage, and intra-articular cement was found in $29(49 \%)$. The abrasive constituent has been isolated, and the implications of this damage discussed (Isaac et al 1987). It is of practical importance to identify the source of the cement in order to minimise its effects on socket wear and loosening. Some of the free cement particles are no doubt the result of the surgical technique, but others are due to the design of the prosthesis; the acetabular component would appear to be the more likely source because of its proximity, exposed area (unless covered by a flange) and the effects of impingement of the neck of the stem against any protruding cement.

An opportunity to study this problem presented itself when a collection of Charnley press-fit sockets, obtained at post-mortem, became available. In the evolution of the Charnley low friction arthroplasty (LFA) there was a time when a series of uncemented metalbacked high density polyethylene (HDP) press-fit sockets (Fig. la) were used with a cemented stem. After reaming the acetabulum the press-fit socket was inserted with the central HDP spigot engaging into the pilot hole of the acetabulum (Fig. 1b). No attempt was made to restrict

G. H. Isaac, PhD, Biomechanical Engineer

B. M. Wroblewski, FRCS, Consultant Orthopaedic Surgeon

Centre for Hip Surgery, Wrightington Hospital, Appley Bridge, near Wigan, Lancashire WN6 9EP, England.

J. R. Atkinson, DPhil, Senior Lecturer, Department of Metallurgy

D. Dowson, FRS, Head of the Department of Mechanical Engineering University of Leeds, Leeds LS2 9JT, England.

Correspondence to Dr G. H. Isaac.

C 1990 British Editorial Society of Bone and Joint Surgery $0301-620 X / 90 / 1$ R $50 \$ 2.00$

J Bone Joint Surg [Br] 1990; 72-B : 149-50 rotation of the socket around its central axis, in the hope that this freedom would reduce the likelihood of unidirectional wear, thus avoiding impingement and loosening. Between November 1962 and December 1965, 336 such sockets were inserted, though their use was subsequently abandoned. This present study reviews those press-fit sockets which have become available. It sought to determine the extent of cement damage and to identify the source of the intra-articular cement; it was not concerned with the reasons that the design failed.

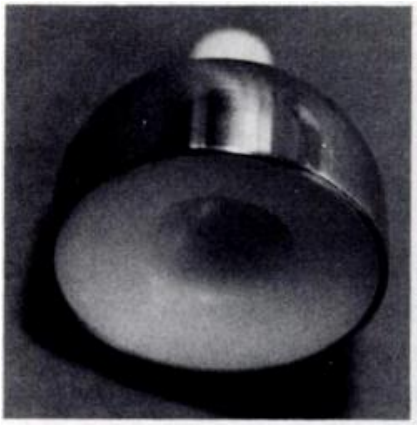

Fig. 1a

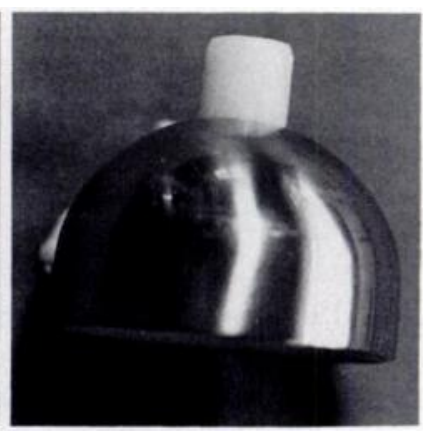

Fig. Ib
Material and method. Of the post-mortem specimens bequeathed to the late Sir John Charnley, 15 were of the press-fit variety. They were excised intact with the surrounding tissues and stored in formalin until examination. The socket bore was examined visually to see if it contained acrylic cement. Then, using dental casting cement, casts of the socket bore were made and dimensional changes were measured using the shadowgraph technique.

Results. Of the 15 sockets, 10 were from women and five from men. Eight were from the right hip, seven from the left. The mean age of the patients at the time of the arthroplasty was 69 years (range 48 to 79 ) and their mean 